\title{
Mathematical models used to describe the properties of magneto-rheo- logical elastomers
}

\author{
JEL: L62 DOI: 10.24136/atest.2019.074 \\ Data zgłoszenia: 15.12.2018 Data akceptacji: 08.02.2019
}

The paper presents and discusses mathematical models that are most widely used to describe the properties of magnetorheological elastomers (MREs). Magnetic elastomers are non-traditional engineering materials with an ever increasing number of practical applications in various areas of industry including transport.

Key words: magnetorheological elastomers, mathematical model, intelligent materials

Introduction

Magnetorheological elastomers (MREs) are a group of intelligent materials. They combine the elasticity of elastomers with good magnetic properties of ferromagnetic materials. These unique properties made them so popular in mechanical engineering. The mechanical properties of MREs can be modified to some extent by application of external magnetic field. For this reason, the main area of their application are vibration damping and absorption systems.

From the researchers' point of view the issue of interest is mathematical modelling of the properties of these non-traditional materials. Such modelling will enhance their use in the engineering process. New, innovative applications can be proposed as a result. There are a number of MREs applications that could be mentioned here. Let us focus on applications related to transport which include: bushings for automotive industry (reduction of linear and turning displacements of vehicle wheels) [9], automobile suspensions (measurement of forces and displacements) [7], vibration isolators (monitoring and reduction of vehicle seating vibration) $[5,19]$. There are number of mathematical models that can be used to describe the properties of magnetorheological elastomers [15]. The most widely used will be discussed further in this paper. They are grouped by the scale at which they describe the material. The interaction between individual ferromagnetic particles or their structures between themselves and with the composite matrix is analysed at the microscale level. Alternatively, there is a group of models describing the situation at the macroscale level. They are based on determining the relationship between the type of input and the response of the material in consideration.

\section{Micro-scale models}

The first models describing the behaviour of MREs in micro scale were based on the research on magnetorheological liquids. Models of this kind are based on the analysis of the interaction between the adjacent particles. For this reason, they are often called dipole models.

A one-dimensional quasi-static model based on a dipolar interaction between particles in a pre-determined structure is presented in [12]. The model assumes perfectly spherical and uniform ferromagnetic particles that are arranged in ideal chain structures with equal spacing between centres. A model considering non-linear magnetic phenomena taking place inside the material could be formulated as a result, described by the following equation:

$$
\Delta G \cong \frac{\phi B_{s}^{2}}{2 \mu_{r} \mu_{0}\left(\frac{r_{0}}{d}\right)^{3}}, \quad \text { for } \varepsilon<0.1
$$

where: $\Delta G$ - absolute MR effect, $B_{S}$ - saturation flux density, $\phi$ - volume fraction of ferromagnetic particles, $\mu_{r}$ - relative magnetic permeability of particles, $\mu_{0}$ - magnetic permeability of vacuum, $r_{0}$ - initial distance between particle centres, $d$ - particle diameter, $\varepsilon-$ strain.

Similar assumptions were adopted in [3] for computer simulations to determine the most efficient content of ferromagnetic particles in a composite. The elastic modulus of the material in the absence of external input was calculated with equation (2) described in more detail in [11]. It was demonstrated that the most efficient fraction of ferromagnetic material is $27 \%$. At this fraction the magnetorheological effect had the greatest magnitude. This has been confirmed by a great number experimental results. The expressions describing the interactions between the dipoles were used to derive the relationship given below (3) For a single chain of particles it is equivalent to equation (1) if a numerical factor of 1.202 is applied [3].

$$
\begin{gathered}
G_{0}=\left(1+1.25 \phi+14.1 \phi^{2}\right) \cdot G_{m}, \\
\Delta G \cong \frac{3 \phi \mu_{0} M_{s}^{2}}{5\left(\frac{r_{0}}{d}\right)^{3}} .
\end{gathered}
$$

where: $G_{0}$ - modulus in the absence of magnetic field, $G_{m}$ - modulus of the matrix material, $M_{S}$ - magnetisation saturation

Relationships describing the interactions between dipoles in the whole chain of particles were also derived. This kind of model has been presented in $[8,21,23]$, in the form of equations (4) and (5).

$$
\begin{gathered}
\Delta G=\frac{9 \phi C m_{1}^{2}\left(4-\gamma^{2}\right)}{8 \pi^{2} r_{0}^{2} a^{3} \mu_{0} \mu_{r}\left(1+\gamma^{2}\right)^{\frac{7}{2}}} \\
G=3 \phi \mu_{0} \mu_{r} \beta^{2} H^{2}\left(\frac{a}{r_{0}}\right)^{3} C\left[\left(\frac{10}{A^{2}}+\frac{2}{B^{2}}\right)+\frac{48 \beta C}{A^{3}}\left(\frac{a}{r_{0}}\right)^{3}\right],
\end{gathered}
$$

where: $\quad A=1-4 \beta \cos ^{3} \gamma\left(\frac{a}{r_{0}}\right)^{3} \cdot C, \quad B=1+2 \beta \cos ^{3} \gamma\left(\frac{a}{r_{0}}\right)^{3}$. $C, \beta=\frac{\mu_{r}-\mu_{e}}{\mu_{p}+2 \mu_{e}}, m_{1}$ - dipole moment of a particle, $a$ - particle diameter, $\gamma$ - shear strain, $C$ - coefficient, $\mu_{e}$ - relative magnetic permeability of elastomer matrix. The structure of a magnetorheological elastomer and dimensions are presented schematically in Fig. 1.

Similar results are obtained by solving the mathematical models (4) and (5). However, for small distances between particles $\left(r_{0}\right)$ model (5) gives much greater changes of the shear modulus. It takes into account the interaction between similar ferromagnetic particles in the magnetic field [8].

The columnar arrangements of particles in MREs result from the action of the magnetic field during the cross-linking process. The quality and the distribution pattern of these structures depend on the magnetic field intensity. This phenomenon is taken into account by the mathematical model presented in [1], as schematically displayed in Fig. 2. 


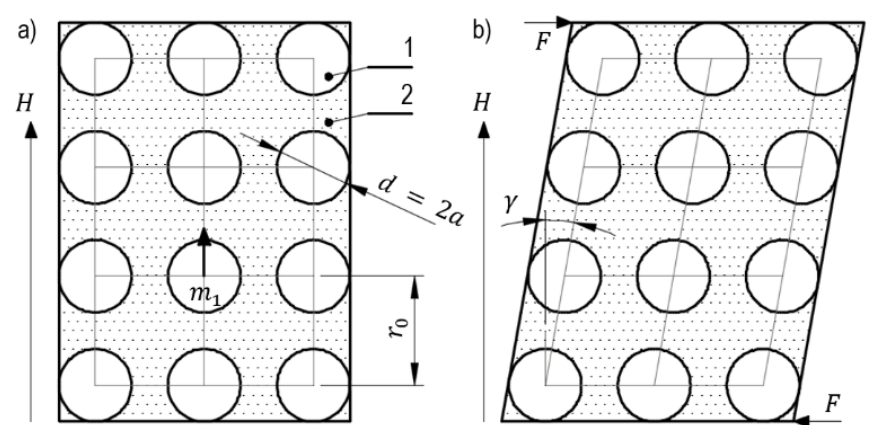

Fig. 1. Schematic of MRE structure; 1 - ferromagnetic particle, 2 - matrix material; derived on the basis of $[8,21,23]$
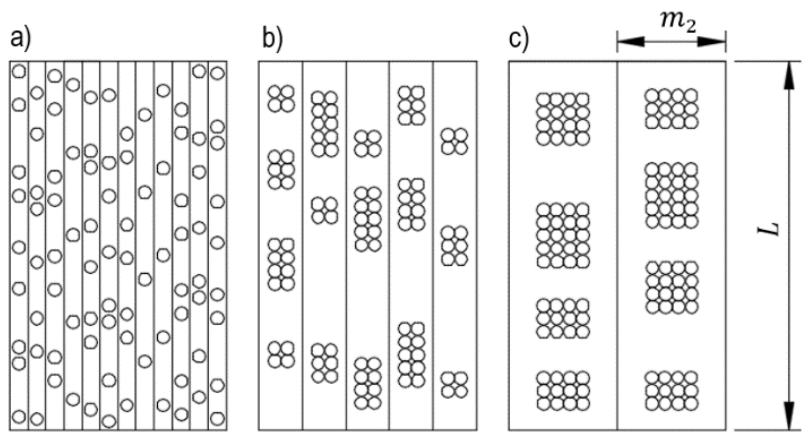

d)

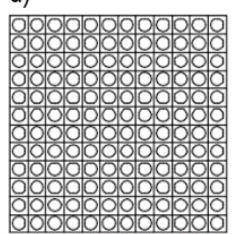

e)
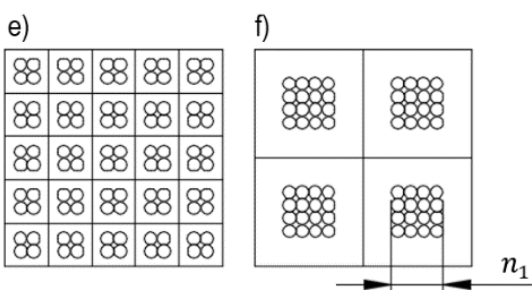

Fig. 2. Schematic representation of structures created in MERs by application of a magnetic field; a)-c) views parallel to columns, d)-f) views perpendicular to columns; a) and d) without magnetic field, b) and e) low intensity magnetic field, c) and f) high intensity magnetic field; derived on the basis of [1].

Model (6) is based on three assumptions. The composite can be split into blocks of identical volume and dimensions of $m_{2} \times m_{2} \times L$. Additionally, quadrilateral columns of uniform thickness $-n_{1}$ can be distinguished in each block. Each column was assumed to contain the same volume of ferromagnetic particles. For the specimens prepared in this research, subjected to low-intensity magnetic field, the relationship (6) and equations (1) and (3) give similar results [1]. This is due to the assumed perfect chain structure which, however, does not happen in reality. The model under discussion has broad application potential in describing the relationships between the composite microstructure and its properties.

$$
\Delta G=\frac{\left(\mu_{\|}-\mu_{\perp}\right) H^{2} \sin \gamma \cdot \cos \gamma}{\gamma},
$$

where: $\mu_{\|}-$magnetic permeability of a block parallel to the column axis, $\mu_{\perp}$ - magnetic permeability of a block perpendicular to the column axis.

The composite properties are influenced by the size of the ferromagnetic particles added in the production process. The size and magnetic saturation of the ferromagnetic particles is considered in model (7) proposed in [24]. This model is different from the previously described ones. Here, the iron particles are assumed to be coated by a magnetisable layer composed of polymer gel and ferrite nanoparticles. The structure of such composites is presented schematically in Fig. 3. Perfectly spherical ferromagnetic particles arranged in an ideal chain structure were assumed as in the previous models. According to the presented model, the addition of nanoparticles increased the shear modulus value.

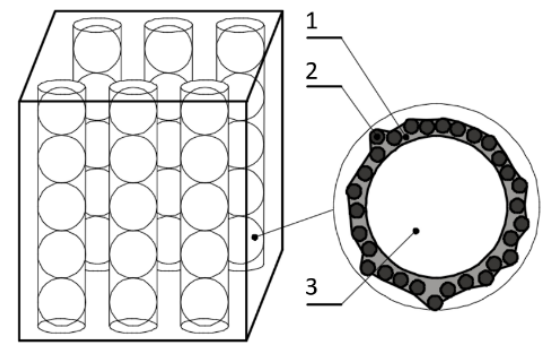

Fig. 3. Structure of MRE containing nanoparticles; 1 - polymer gel, 2 - nanoparticle, 3 - particle; derived on the basis of [24].

A mathematical model of MRE containing ferromagnetic particles of different sizes (8) and (9) is proposed in [18]. The difference in stiffness of the composite depending on the fraction of smaller particles in the total ferromagnetic content was determined. With the diameter of large particles ten times greater than the diameter of the smaller ones the efficient content was $23.2 \%$ [18].

$$
\begin{array}{cc}
\Delta G \cong \frac{\phi B_{s}^{2}}{2 \mu_{r} \mu_{0}\left(\frac{r_{0}}{d}\right)^{3}}, & \text { for } x \leq 23.2 \%, \\
\Delta G \approx \frac{(73.64 x-17.12) \phi \mu_{0} H^{2}}{\left(9 \mu_{0} H+2.72\right)^{2}} & \text { for } x>23.2 \%, \\
+\frac{0.908(1-x) \phi \mu_{0} H^{2}}{\left(\mu_{0} H+0.091\right)^{2}} &
\end{array}
$$

where: $x=\frac{\phi_{s}}{\phi_{s}+\phi_{l}}, \phi_{s}$ - volume fraction of smaller particles, $\phi_{l}-$ volume fraction of large particles, $\phi_{n}-$ volume fraction of nanoparticles.

\section{Macro scale models}

The next group of models relates to macro scale analysis. These models are created by serial or parallel combination of mathematical rheological models of Hook and Venant solid bodies and of Newtonian liquid. They describe ideally elastic strain, ideally plastic deformation and ideal flow states respectively. The constitutive equations obtained by application of the above-mentioned rheological models combine stress, strain and time relationships.

In [14] a modified Klevin-Voigt model is used to model the isotropic MRE behaviour under cyclic compression. The conventional elastic element was replaced with an element having a non-linear behaviour. This model is displayed in Fig. 4 below and it is described by equation (10).

$$
G=\frac{3}{4} \frac{\phi \mu_{0} \mu_{r}\left(\frac{d}{r_{0}}\right) H^{2}\left(\mu_{r}-\mu_{e}\right)^{2} \cdot\left[\frac{4 r_{0}}{d}\left(\phi_{n}-1\right)-3 \phi_{n}\right]^{2}}{\sqrt{1+\gamma^{2}}\left\{3 \sqrt{1+\gamma^{2}}\left(\mu_{r}+\mu_{e}\right)+\left[\frac{4 r_{0}}{d}\left(\phi_{n}-1\right)-3 \phi_{n}\right]\left(\mu_{r}-\mu_{e}\right)\right\}^{2}}
$$




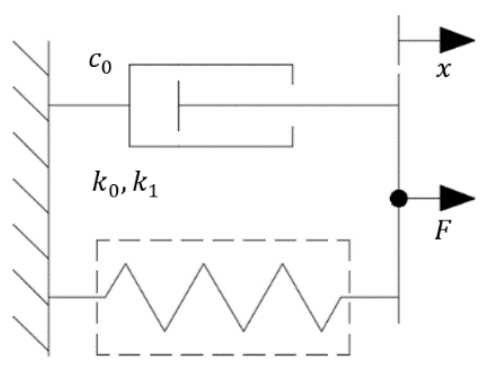

Fig. 4. The MRE model incorporating a non-linearly elastic element has been derived on the basis of [14].

$$
F=c_{0} \dot{x}+f(x),
$$

where: $c_{0}=c_{O a}+c_{0 b} \cdot B, f(x)=k_{0} x^{2}+k_{1} x=k_{o a}+k_{0 b} \cdot B$, $k_{1}=k_{1 a}+k_{1 b} \cdot B ; c_{O a}, c_{0 b}, k_{o a}, k_{0 b}, k_{1 a}, k_{1 b}$ are the values of the model coefficients.

Combining of the Maxwell and Ramberg-Osgood models is proposed in [6]. These two models are used respectively to represent the viscoelastic properties of an MRE and its non-linear properties. The schematic of the combination model is presented in Fig. 5 . The behaviour of the Ramberg-Osgood model during loading and unloading is described by equations (11) and (12) respectively. The Maxwell model described with a force and displacement is presented in (13). The total force resulting from parallel coupling of the two above models is calculated according to (14).

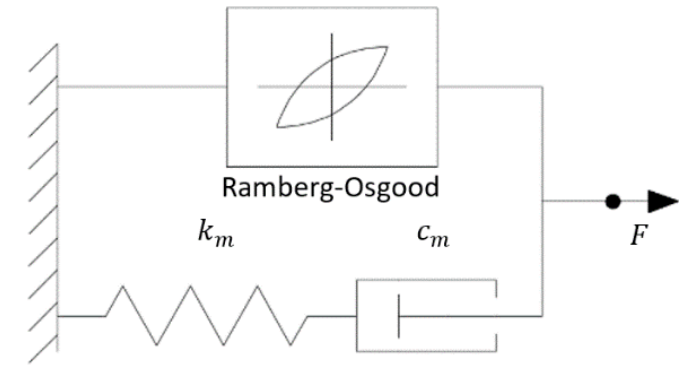

Fig. 5. The MRE model incorporating a non-linearly Ramberg-Osgood model derived on the basis of [6].

$$
\begin{gathered}
x=\frac{F_{r}}{k_{0}}+\frac{F_{r}}{k_{0}}\left(\frac{F_{r}}{F_{y}}\right)^{r-1}, \\
x-x_{i}=\frac{F_{r}-F_{i}}{k_{0}}+\frac{F_{r}-F_{i}}{k_{0}}\left|\frac{F_{r}-F_{i}}{2 F_{y}}\right|^{r-1}, \\
\frac{d x}{d t}=\frac{1}{k_{m}} \frac{d F_{m}}{d t}+\frac{F_{m}}{c_{m}}, \\
F=F_{r}+F_{m},
\end{gathered}
$$

where: $x$ - displacement, $F_{r}$ - force applied to Ramberg-Osgood model, $k_{0}$ - shear stiffness, $r$ - coefficient of shape of the hysteresis loop, $F_{y}$ - force equivalent to yield point, $F_{i}$ - ultimate force, $x_{i}$ - ultimate displacement, $F_{m}$ - force applied to the Maxwell model, $k_{m}$-spring constant, $c_{m}$-damping coefficient, $F$ - total input force.

A model combining the Maxwell model with the model of elasticperfectly plastic material is presented in $[13,17]$ and displayed in Fig. 6 below.

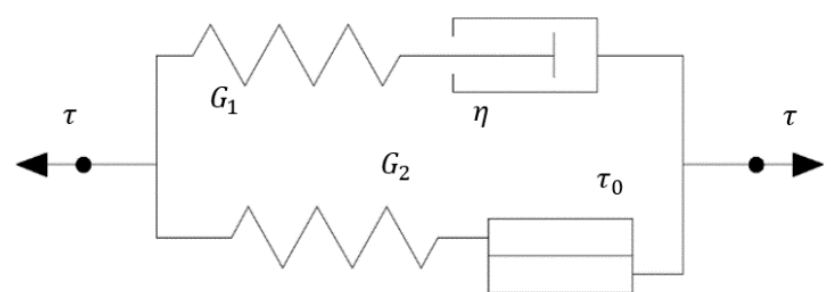

Fig. 6. Schematic of an elastic-viscoplastic model derived on the basis of [17].

For such a model the stress-strain relationships are given by equations (15) and (16):

$$
\begin{array}{rr}
\tau+\frac{\eta}{G_{1}} \dot{\tau}=G_{2}\left(\gamma+\eta \dot{\gamma} \frac{G_{1}+G_{2}}{G_{1} G_{2}}\right)-G_{2} \gamma_{k}+\tau_{02} \text { sign } \dot{\tau}, \\
\tau+\frac{\eta}{G_{1}} \dot{\tau}=\eta \dot{\gamma}+\tau_{0} \operatorname{sign} \dot{\tau}, & \text { when } \tau_{2}= \\
\tau_{0} \operatorname{sign} \dot{\tau},
\end{array}
$$

where: $\tau_{0}$ - shear stress, $\tau_{0}$ - yield point of ideally plastic material, $\dot{\tau}$-stress rate, $\eta$-viscosity, $G_{1}, G_{2}$ - shear moduli, $\gamma$-shear strain, $\gamma_{k}$-strain at the time of load application in an ideally plastic material, $\dot{\gamma}$ - strain rate.

Simplification of this model was proposed in [22]. This was supported by the observation that some input frequencies cause small changes in the material. Assuming their invariability, the viscous element was removed from the model. This largely facilitated the composite analysis and modelling process. The schematic of an elasticplastic body with a linear kinematic reinforcement is presented in Fig. 7.

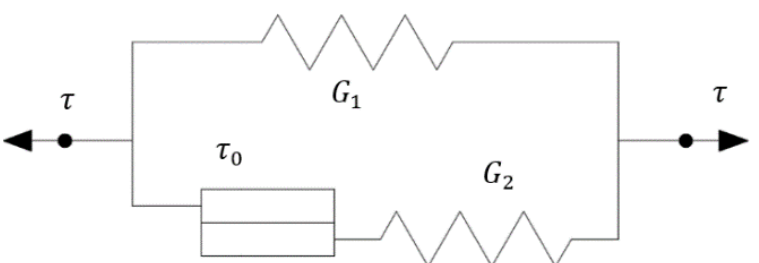

Fig. 7. Schematic of an elastic-plastic body with a linear kinematic reinforcement derived on the basis of [17].

The constitutive equations describing its behaviour are given by equations (17) and (18).

$$
\begin{array}{lr}
\tau=\gamma\left(G_{1}+G_{2}\right)-G_{2} \gamma_{k}+\tau_{0} \operatorname{sign} \dot{\tau}, \\
\tau=\gamma G_{1}+\tau_{0} \operatorname{sign} \dot{\tau}, \quad \text { when } \tau_{2}= \\
\tau_{0} \operatorname{sign} \dot{\tau},
\end{array}
$$

Worthwhile noting is the model proposed in [2]. It considers the viscoelastic properties of the matrix material, change of the composite properties after application of magnetic field and displacement of ferromagnetic particles in relation to the composite matrix. The effect of magnetic field on the MRE behaviour was determined with equation (1) derived in [12] as referred earlier in this paper. It concerns a dipole model and assumes, inter alia, arrangement of particles in a columnar pattern. The model is schematically presented in Fig. 8 and the constitutive relationships are described by equations (19) to (24). 


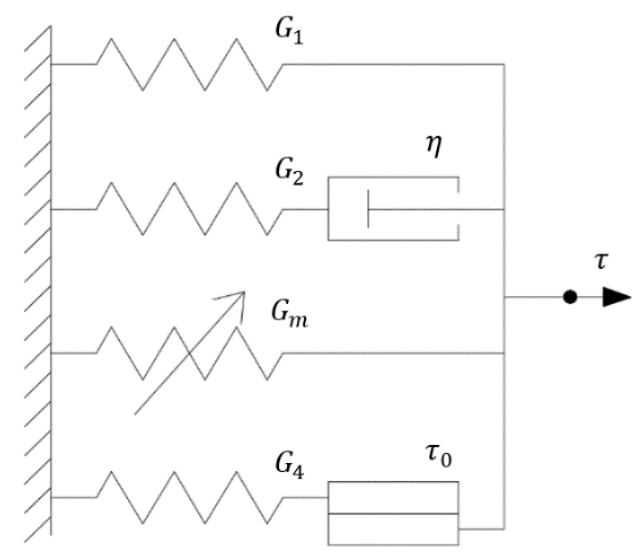

Fig. 8. The rheological model considering the dynamic properties of MREs is based on [2].

$$
\begin{gathered}
\tau=\tau_{1}+\tau_{2}+\tau_{3}+\tau_{4}, \\
\tau_{1}=G_{1} \gamma, \\
\tau_{2}=\eta \dot{\gamma}_{1}=G_{2} \gamma_{2} \quad \text { where } \gamma=\gamma_{1}+\gamma_{2} \\
\tau_{3}=\frac{27 \phi^{2} \mu_{0}\left(\mu_{r}-1\right)^{2} M_{s}^{2} H^{2} \gamma\left(4-\gamma^{2}\right)}{4 \pi^{2} \mu_{e} \mu_{0}\left(1+\gamma^{2}\right)^{\frac{5}{2}}} \\
\dot{\tau}_{4}=G_{4} \dot{\gamma} \quad \text { when }-\tau_{0}<\tau<\tau_{0}, \\
\tau_{4}=\tau_{0} \operatorname{sign} \dot{\gamma} \quad \text { when }-\tau_{0} \geq \tau \\
\text { or } \tau_{0} \geq \tau
\end{gathered}
$$

There is a great number of mathematical models used to describe these materials as reported in the literature. This being so, the KelvinVoigt model is by far the most popular one. It is quite often modified in order to maximise agreement between the experimental and modelling (simulation) data [16]. The Kelvin-Voigt model describes the behaviour of a linearly viscoelastic material. Note that the rheological properties of such materials change over time. This model enables a qualitative description of certain properties of solid bodies which result from their non-ideal elasticity. They include: the mechanical hysteresis loop, decay of free vibration, retarded elasticity and creep [4]. The Kelvin-Voigt model is made by combining an ideally elastic body connected in parallel with an ideally viscous fluid. The structure of the model is based on the Young's modulus and viscosity $\eta$. The KelvinVoigt model is schematically presented in Fig. 9 . The relevant physical equation of state is given below (25).

$$
\sigma=E \varepsilon+\eta \dot{\varepsilon}
$$

A major advantage of this model is its simplicity. It results from a small number of input parameters that need to be determined. In certain cases, however, this may lead to an unsatisfactory level of accuracy.

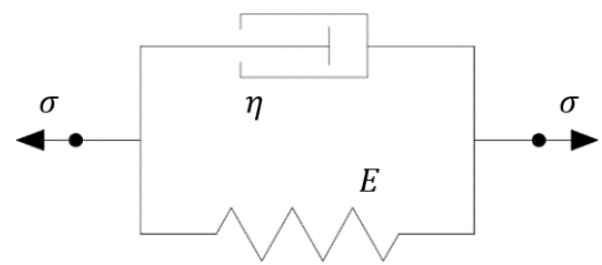

Fig. 9. Schematic of the Kelvin-Voigt viscoelastic model
A detailed evaluation of agreement between the measurements and the values obtained with the Kelvin-Voigt is often missing in the research papers. The reported outputs are most often limited to giving the E-moduli or their variation as a function of magnetic field parameters, frequency or amplitude of input. However, the issues related to the accuracy of representation of the material behaviours in a stressstrain system must not be ignored in the case of MREs [16].

\section{Final conclusions}

This presentation of mathematical models used to describe the properties of magnetorheological elastomers does not tackle all the issues pertaining to the subject. There are a number of other papers that could be referred to, including inter alia $[10,20,25]$. This paper succeeded in demonstrating the scale, diversity and the level of complexity of the mathematical tools used for modelling the change of properties of MREs. Future research should focus on determining a series of material properties defining efficient and long-term use of MREs in technical equipment. Worthwhile noting effect of temperature, time and fatigue resistance on the performance characteristics of the composites under analysis. The properties of elastomers depend on the temperature. As such, it is necessary to determine its effect on the changes taking place in the composite material. Moreover, their properties also change over time due to aging. Determination of fatigue performance curves is indispensable for ensuring predictable operation of vibration damping devices which comprise a majority of MREs applications.

Bibliography:

1. Chen L., Gong X. L., Li W. H.: Microstructures and viscoelastic properties of anisotropic magnetorheological elastomers, 2007, Smart Materials and Structures, vol. 16, no. 6 .

2. Chen L., Jerrams S.: A rheological model of the dynamic behaviour of magnetorheological elastomers, 2011, Journal of Applied Physics, vol. 110.

3. Davis L. C.: Model of magnetorheological elastomers, 1999, Journal of Applied Physics, vol. 85, no. 6.

4. Derski W., Ziemba S.: Analiza modeli reologicznych, Warszawa 1968, Państwowe Wydawnictwo Naukowe.

5. Du H., Weihua L., Zhang N.: Semi-active variable stiffness vibration control of vehicle seat suspension using an MR elastomer isolator, 2011, Smart Materials and Structures, vol. 20, no. 10.

6. Eem S. H., Jung H. J., Koo J. H.: Modeling of Magneto-Rheological Elastomers for Harmonic Shear Deformation, 2012 IEEE Transactions on Magnetics, vol. 48, no. 11.

7. Elie L., Ginder J., Mark J., Nichols M., US Patent 5814999. Method and apparatus for measuring displacement and force, (1998).

8. Fang S., Gong X. L., Zhang X. Z., Zhang P. Q.: Effect of preconfiguration on performance of magnetorheological elastomers, 2005, Electrorheological Fluids and Magnetorheological Suspensions, Proceedings of the Ninth International Conference, China, 29 August - 3 September, 2004, ISBN: 978-981-256-122-0, pp. 134-139.

9. Ginder J. M., Nichols M. E., Elie L. D., Clark S. M.: Controllablestiffness components based in magnetorheological elastomers, 2000, Proc. SPIE3985, Smart Structures and Materials 2000: Smart Structures and Integrated Systems, vol. 3985.

10. Guo F., Du Ch. Li R.: Viscoelastic Parameter Model of Magnetorheological Elastomers Based on Abel Dashpot, 2014, Advances in Mechanical Engineering, vol. 2014, Article ID 629386.

11. Guth E.: Theory of Filler Reinforcement, 1945, Journal of Applied Physics, vol. 16, is. 1. 
12. Jolly M. R., Carlson J. D., Munoz B. C.: A model of the behaviour of magnetorheological materials, 1996, Smart Materials and Structures, vol. 5, no. 5, pp. 607-614.

13. Kaleta J., Lewandowski D., Ziętek G.: Inelastic properties of magnetorheological composites: II. Model, identification of parameters, 2007, Smart Materials and Structures, vol. 15, no. 5.

14. Koo J. H., Khan F., Jang D. D., Jung H. J.: Dynamic characterization and modelling of magneto-rheological elastomers under compressive loadings, 2009, Journal of Physics: Conference Series, vol. 19, no. 1.

15. Kukla M.: Kształtowanie cech materiałowych elastomerów magnetoreologicznych w budowie maszyn, praca doktorska, Politechnika Poznańska, Poznań 2018.

16. Kukla M., Górecki J., Malujda I., Talaśka K., Tarkowski P.: The Determination of Mechanical Properties of Magnetorheological Elastomers (MREs), Procedia Engineering, vol. 177, p. 324-330, 2017

17. Lewandowski D.: Właściwości łłumiące kompozytów magnetoreologicznych. Badania, modele, identyfikacja, praca doktorska, Politechnika Wrocławska, Wrocław 2005.

18. Li W. H., Zhang X. Z.: A study of the magnetorheological effect of bimodal particle based magnetorheological elastomers, 2010, Smart Materials and Structures, vol. 19, no. 3.

19. Li W., Zhang X., Du H.: Development and simulation evaluation of a magnetorheological elastomer isolator for seat vibration control, 2012, Journal of Intelligent Material Systems and Structures, vol. 23, no. 9, pp. 1041-1048.

20. Li W. H., Zhou Y., Tian T. F.: Viscoelastic properties of MR elastomers under harmonic loading, 2010, Rheologica Acta, vol. 49, is. 7, pp. 733-740.

21. Shen Y., Golnaraghi M. F., Heppler G. R.: Experimental Research and Modeling of Magnetorheological Elastomers, 2004, Journal of Intelligent Material Systems and Structures, vol. 15, no. 1, pp. 27-35.
22. Zając P.: Właściwości tłumiące elastomerów magneto-reologicznych. Badania, modele, identyfikacja, praca doktorska, Politechnika Wrocławska, Wrocław 2014.

23. Zhang W., Gong X. L., Chen L.: A Gaussian distribution model of anisotropic magnetorheological elastomers, 2010, Journal of Magnetism and Magnetic Materials, vol. 322, is. 23, pp. 37973801.

24. Zhang X., Li W., Gong X. L: An effective permeability model to predict field-dependent modulus of magnetorheological elastomers, 2008, Communications in Nonlinear Science and Numerical Simulation. vol. 13, is. 9, pp. 1910-1916.

25. Yu Y., Li Y., Li. J: Parameter identification of a novel strain stiffening model for magnetorheological elastomer base isolator utilizing enhanced particle swarm optimization, 2015, Journal of Intelligent Material Systems and Structures, vol. 26, no. 18., pp. 2446-2462.

\section{Modele matematyczne stosowane do opisu właściwości elastomerów magneto-reologicznych}

W artykule przedstawiono, wraz z omówieniem, najczęściej stosowane modele matematyczne wykorzystywane do opisu właściwości elastomerów magnetoreologicznych. Są to nieklasyczne materiały inżynierskie, których liczba praktycznych zastosowań, również w środkach transportu, stale wzrasta.

Słowa kluczowe: elastomery magnetoreologiczne, model matematyczny, materiały inteligentne

Authors:

Mateusz Kukla, PhD. Eng. - Chair of Basics of Machine Design, Poznan University of Technology, 3/424 Piotrowo St., 60-965 Poznań, Poland, e-mail address: mateusz.kukla@put.poznan.pl, tel.: +48 612244514

Krzysztof Talaśka, PhD. Eng. - Chair of Basics of Machine Design, Poznan University of Technology

Asc. Prof. Ireneusz Malujda, PhD Eng. - Chair of Basics of Machine Design, Poznan University of Technology 